Western University Scholarship@Western

Education Publications

Education Faculty

2004

\title{
School Mathematics in the Era of Globalization
}

Immaculate Kizito Namukasa

The University of Western Ontario, inamukas@uwo.ca

Follow this and additional works at: https://ir.lib.uwo.ca/edupub

Part of the Education Commons

Citation of this paper:

Namukasa, I. (2004). School mathematics in the era of globalization. Interchange, 35(2), 209-227. Available at http://www.springerlink.com/content/18221k340185w43k/. 


\title{
School Mathematics in the Era of Globalization
}

\section{IMMACULATE NAMUKASA University of Alberta}

\begin{abstract}
This essay reviews the principles motivating contemporary critical mathematics discourses. Drawing from varied critical discourses including ethnomathematics, critical theory, post-structural theory, and situated and ecological cognition, the essay examines the pragmatics of critiques to the privileged role of school mathematics in the era of globalization. Critiques of modern school curricula argue that globalization practices linking education to technological and economic development are increasing, and the curriculum is being redefined through discourses of privatization, national standards, and global competitiveness. Globalization has reinforced the utilitarian approach to schoolmathematics and the Western bias in the prevailing mathematics curricula, as well as helped to globalize pervasive mathematical ideologies. In most instances, a newfound status that mathematics is enjoying in this era of globalization is not well deserved, as school mathematics can no longer be considered culturally, socially, politically, nor economically neutral. In particular, school mathematics is increasingly critiqued as a cultural homogenizing force, a critical filter for status, a perpetuator of mistaken illusions of certainty, and an instrument of power. With such concerns it is becoming more evident that mathematics learning and education have implications for building just and democratic societies. As an African female scholar who is now living in Canada, I reflect on what the critical stance might mean for contexts with which I am
\end{abstract}


familiar. I discuss the challenges of school mathematics with a view to improving curriculum and pedagogy so as to raise the awareness of teachers and learners to the questionable assumptions from which mathematics derives its prestige. The mathematics curriculum is central to cultivating values as well as fostering the conscientization of learners.

KEYWORDS: Globalization, school mathematics, mathematical validity, Western mathematics, critical discourses, utilitarian view, mathematics development, democracy, pedagogy, curriculum. 
School mathematics is traditionally perceived as an elitist subject for more academically oriented learners. In most countries, especially Southern countries, mathematics is a criterion for admission to universities and colleges. At colleges and universities mathematics has become interwoven with other disciplines such as psychology and sociology and it is associated with most of the developments of the technological, information age. Some scholars are concerned that heightened description, prescription, and prediction of the physical and social sciences boosts the utilitarian thrust towards mathematics. According to critiques of school mathematics this newfound status needs to be examined, for there are instances where it is not well deserved. As Polya (1957/1973) has argued, part of the honor accorded to school mathematics is dubious, since school mathematics is amongst the least popular subjects for students. School mathematics has also been critiqued for, with the help of colonialism, reinforcing a Western/Eurocentric approach in the prevailing curriculum and for helping to globalize particular kinds of mathematical technologies and ideologies (Bishop, 1997; D’Ambrosio, 1990).

This paper examines the privileged role of school mathematics in the era of globalization. This privilege is not without justification. Mathematics is a way of knowing and of existing in the world; it is difficult to imagine our daily lives without basic mathematical technologies such as measurement, counting, comparing, and locating. Historical and contemporary evidence show that every human culture (however small) not only motivated by utility but also by aesthetics, religion, or enchantment, is capable of developing some form of mathematics (Davis, P. \& Hersh, 1981; Ghever Ghese, 1991). Mainstream mathematics, such as the mathematics curriculum in most parts of the world, is applicable to wide areas of experience and is integrated into other disciplines. Basic mathematics is a globally understood language; it is an approach to being in, engaging with, and relating to the world, and to perceiving and understanding the structure of our worlds. 
Both the social and physical worlds are being understood from a mathematical view at an increasing rate.

P. Davis and Hersh (1986) maintain that the application of mathematics to almost every aspect of the human world is often established on questionable assumptions and has problematic implications. Skovsmose (1990) argues that school mathematics has political implications as it favors certain groups of students, stratifies society, and serves as an introduction to an ideology characterized by certainty, idealism, and rationalism. It appears the modern world is filled with the spirit of Descartes, a dream about a universal method whereby all human problems could be worked out rationally, systematically, and by logical computation (P. Davis \& Hersh, 1986; Jardine, 1998). Due to the wide range of application and internationalization of modern mathematics, school mathematics is implicated in theories about building democratic societies. In addition the long held view that mathematics has nothing to do with culture and politics is flawed.

As an African scholar, I have lived particular challenges of school mathematics, first as a school mathematics student then as a school mathematics teacher, a post-graduate mathematics and mathematics education student, and now as a mathematics educator, and always as a member of an increasingly mathematized society. In the post-colonial era and now with globalization, school mathematics and school at large in countries in the South is indeed a cultural homogenizing force, a critical filter for status, a perpetuator of mistaken illusion of certainty and, an instrument of power. Moreover even in countries in the North some recent reforms, particularly those driven by challenges of globalization, undermine efforts towards more democratic and socially responsive curricula. It is often an overlooked challenge for teachers, educators and curriculum designers to understand how the broader aspects of society are constituted by (as well as constitute) the specific and local contexts of classrooms. In this paper referring to critical mathematics discourses including ethnomathematics, critical theory, post-structural theory, and situated and ecological 
cognition theories I examine the pragmatics of criticisms that have arisen around school mathematics for the contexts with which I am familiar.

Studies in the emerging field of ethnomathematics examine the history of mathematics, the cultural anthropology of ancient empires, and the mathematics of traditional societies to understand non-western mathematical ways of knowing (D'Ambrosio, 1985). Ethnomathematics scholars, such as D'Ambrosio and Gerdes, analyze the differences as well as invariance of mathematical traditions across and within identifiable cultural groups. Studying the mathematical notions and skills of varied cultures, cultural scholars maintain that mathematical thinking is developed and used in specific cultural contexts with specific needs and ways of life. They analyze the relationship between culture and mathematics, questioning the predominant view that mainstream mathematics is cultureneutral.

Critical theorists, such as Apple, Bishop, and Skovsmose, are concerned with ideologies and institutions that support and maintain ruling power structures. They maintain that a non-critical understanding, teaching, and useof mathematics may simply perpetuate oppressive values, pervasive ideologies, and power structures. Critical theorists examine how school mathematics is either enhancing or debilitating a democratic society. To promote a democratic society, critical theorists advocate for a curriculum that teaches societal values.

Post-structuralists, such as Walkerdine, maintain that mathematical meaning is determined by a play of signs and a play of difference, and by a silenced, suffocated other. Drawing from analyses such as Foucauldian analysis and Bourdieu's socio-cultural analysis, post-structuralists are interested in how differences, such as differences in mathematical ability, are lived. Post-structuralists focus on how school mathematics is socially organized and maintained with the hope that understanding of differences will influence analyses of learning. 
Situated cognition scientists such as Saxe and Posner, and ecological cognition scholars such as Jardine and B. Davis emphasize that mathematics is situated within the social, material, and cultural contexts in which it arose (or arises) as a tool for human use and play. Situated and ecological cognition scholars maintain that learning mathematics should happen in context and as a social and human activity rather than a non-corporeal discipline.

This is an over simplified description of the fields of study that I have grouped under the umbrella term critical (or reconceptionalist) discourses. For purposes of this essay and due to the limited space I have underplayed the differences that exist within varied fields of study. Also other reconceptionalist schools for instance the socio-cultural accounts of learning and historical theories are beyond the focus of my preliminaryexploration of principles motivating contemporarycriticisms of school mathematics. In general, critiques of school mathematics examine the implications of modern mathematics as a product of centuries of Cartesian thinking that sought to elevate mathematics beyond the humane. Drawing from fields as diverse as anthropology, neuroscience, and ecological studies scholars critique the consideration of mathematics as a non-corporeal, entirely rational discipline that is, therefore, value-free. They highlight the importance of context, of situated and of embodied experience plus the place of human agency in mathematics development and education. Researchers propose that considering varied curricula and pedagogical possibilities can help transcend some of the shortcomings of school mathematics (See Confrey, 1995,1999; Davis, B., 2001; D’Ambrosio, 1990). These criticisms, however, have been a major factor in the endless reforms (such as the modern mathematics movement of the 1960s and its backlash - the back to basics movement in North America) that school mathematics has grappled with. In the face of globalization, the challenges and limitations of school mathematics together with the proposed reforms ought to be reexamined. Such an examination might raise critical and mindful awareness (conscientization ${ }^{1}$ ) of students, teachers, and educators and of society as a whole to the questionable assumptions 
from which mathematics derives its prestige.

\section{Globalization and its Links to School Mathematics}

Globalization is a contemporary term used in various ways. To most scholars, globalization refers to the ideological and structural changes that are directed towards an understanding of the interconnection, especially trading, of people in different parts and eras of the world. The present form of globalization involves a combination of broad, cultural, economic, political, and technological forces that are changing the ground rules for human interaction on a worldwide scale (Kachur \& Harrison, 1999). These emerging global ground rules are based on unlimited economic expansion under liberalized trade. In addition globalization involves: practices linking education to technological and economic development;increased privatization; international curriculum harmonization; application of free market economics to education through the policy curricula reforms; and the treatment of education as both work preparation and as a human right (Smith, 2000; Spring, 1998).

The International Mathematics Study, for example, administers a standard mathematics examination to 13-year-old children from various parts of the world. This examination is aimed at studying teaching and learning, but at the same time it also points to some of the challenges of school mathematics in the era of globalization. In what ways should a uniform mathematics curriculum be taught to 13-year-olds around the world? Critical mathematics scholars voice the need to reflect on the value and the benefits of an excellent performance in an international mathematics examination. Assuming that the standard examination is methodologically accurate and not culturally biased (as mathematics itself is), what does it measure? Despite the possible contributions to mathematics teaching (such as enhancing international collaborations), participation in such international studies is likely to promote international curriculum standards that might negatively influence mathematics teaching. 


\section{School Mathematics as a Cultural Homogenizing Force}

The last two decades have brought an increased interest in issues of race, gender, and political democracy in mathematics education. Critical theorists criticize school mathematics for its lingering colonial mentality that continues to consider anything different from it as inferior, requiring the work of civilization (Walkerdine, 1990). Given its Eurocentric nature, Wright (1988) maintains, modern mathematics has tended to underplay the contributions of other cultures, and students are rarely informed about such contributions. Mainstream mathematics continues to mistakenly trace its origin solely to Greece, ignoring its historical bases in Egypt, Babylonia, India, and the Middle East, and the parallel mathematical pursuits of the Chinese, the Japanese, Hindus, and Inca-Aztec cultures (P. Davis \& Hersh, 1981; Ghever Ghese, 1991). If students want to know the resemblances (probable sources or variations) of Western mathematics to mathematical enterprises in nonWestern traditions and their different tracks of inquiry to what resources can they turn? It seems crucial that school mathematics is encouraged to reflect the historical links of modern mathematics to religion, to socially stratified societies, and to early mathematical traditions. The possible "predation" of Pythagoras' theorem (540 B. C.) in an ancient Indian text, Sulbasutras c. in 800-600 B.C and in a Chinese mathematical source in 500-200 B.C, or the fact that Pascal's triangle may have its origin in China 350 years before Pascal might be of pedagogical significance (Ghever Ghese, 1991; Wright, 1998). At the root of the exclusion of historical development of mathematics from mathematics is the long held belief that mathematics transcends humans and, therefore, is a historical.

The historical and contemporary relationships between culture and mathematics illustrate that mathematics is not culture-free. As ethnomathematics scholars argue, all human cultures appear to be capable of "proto" mathematical discourse, and this, rather than the specific Western lineage of mathematical theory and activity, is the basis of the universality of the mathematical ways of knowing. D'Ambrosio (1985), arguing that the 
culturally specific nature of mathematics should be acknowledged, coined the term ethnomathematics to describe the mathematics that is practiced among cultural groups, such as national-tribal societies, labor groups, professional classes, and children of a certain age group. ${ }^{2}$ Researchers interested in ethnomathematics such as Gerdes and Zaslavsky in Africa recommend the incorporation of native cultural forms of mathematics in the school curricula. In nations such as South Africa where particular cultures were at one time politically and economically disempowered this position has caused ethnomathematicians to be accused of ghettoizing and creating tourist curricula (Vithal \& Skovsmose, 1997). Also, at a time when countries in the South are looking for ways of enhancing their participation in the global markets endeavors to localize curriculum seem equally contestable.

More importantly, ethnomathematical studies raise the awareness about other (nonWestern) ways of knowing. Pinxten (1994a) asked whether the world-view present in the, so-called, scientific perspective is present in everybody's experience. Evidence from the Navajo tribe (a native tribe in the United States) illustrated how the Navajo's religion, their holistic world-view, and attention to processes and relations rather than to objects had implications for the development of a curriculum and pedagogy suited for Navajo students (Pixten, 1994a; see also Moore, 1994). Navajo people consider space and existence to be in motion. Pixten (1994b) illustrates how this different world-view is evident in the Navajo's vernacular-language structure in which "to be" and "the sky is blue" are stated as "to go" (p. 90) and "the bluing is taking place" (p. 92). The Navajo's holistic world-view, inevitably, has implications for the learning of concepts such as Euclidean geometry within the Navajo culture.

Ethnomathematics scholars and situated cognition scientists categorize mathematics into school (academic) mathematics and everyday (street) mathematics. Everyday mathematics refers to the mathematical activity that is developed and used outside school in a social context; for example, the use, by certain cultures, of numeration systems 
different from the dominant base 10 system. The Yoruba of Nigeria as was the case with the Aztec of Central America have a complex base 20 system that draws on both additive and subtractive principles for verbal numeration (Saxe \& Posner 1983; Zaslavsky, 1994). In most languages 325 is verbalized in a way that can be expressed as $[(3 \times 100)+(2 \times 10)+$ 5]; that is to say, in base 10 and expressed with additive and multiplicative functions. To the Yoruba people it is $[(2 \times 200)-(4 \times 20)+5]$. Saxe and Posner $(1983)$ postulate that although such a numeration system as the Yoruba's involving subtractive principles would seem to require considerable arithmetic skill to master, it apparently occurs in the context of everyday activities. That for a few isolated cultures, before the Western numeration systems anything beyond two, three, or four was just many is at most times more emphasized than the existence of such complicated mathematical ways of being among African and American native cultures (Ghever Ghese, 1991).

School mathematics, in contrast to everyday mathematics, entails school activities done with the sole purpose of doing mathematics. As B. Davis (2001) asserts, academic mathematics to which school mathematics is committed arose together with, and chiefly in service of, modern science. Consequently, school mathematics greatly supports a capitalist, urbanized, and industrialized consciousness. School mathematics is related to some of the more troublesome aspects of the globalization of academic mathematics in a complex way. Moreover the immediate classroom experiences are not only influenced by the ideologies of mathematics. Daily classroom experiences constitute and perpetuate (and so are capable of transforming) pervasive mathematical ideologies.

Mainstream mathematics has contributed to obscuring both its historical and contemporary tendency to marginalize certain disadvantaged groups. Bishop (1997) and Sleeter (1997) postulate that the view that mathematics began with the Greeks and was developed in Europe and the United States reinforces the assumption that people of European descent are more capable of learning mathematics. For critical theorists, such as 
Sleeter and Bishop, the learning of mathematics should rightfully include the history of mathematics, with an explicit clarification of the perspective used to examine that history.

Not only is the Eurocentric view of the history of mathematics biased in terms of gender and race, modern society places a higher value on symbolic and decontextualized representation than on people's immediate experiences. In this dominant idealized view mathematics is separated and elevated from other academic disciplines and from the dayto-day aspects of life. Cultural and historical theorists continue to gather evidence which demonstrates that the potential, at least, for proto mathematics is a human universal ability (Ghever Ghese, 1991), and that the rudiments of formal mathematical ideas are often grounded in our everyday experiences (Lakoff \& Núñez, 2001).

Furthermore, the traditional school curriculum seems to be more "Newtonian" than "Hookean." Confrey $(1995,1999)$ observes that whereas Hooke a curator at the Royal Society was required to produce practical demonstrations of scientific principles on a weekly basis that Newton formalized in symbolic results, it is Newton that was and still is acknowledged for all (except one - Hooke's law) contributions. In a formalist manner more traditional school curricula usually emphasize formalized results neglecting the material, emotional, and concrete basis of mathematical abstractions. Here the historical roots of academic mathematics in "Greek civilization, with its substantial slave population" appear to be mirrored; Greek civilization "allowed a small elite the freedom to pursue activities which had no practical significance" (Ghever Ghese, 1991, p. 129). Also in India where our number systems originated traditional mathematical pursuits, as a result of transmission of mathematics in Sutra form - abbreviated verses that took elaborate explanations to the uninitiated, were confined to elite families of the caste system (Ghever Ghese, 1991).

In addition to being formalistic and elitist, school mathematics has often been slow to accommodate recent innovation in mathematics, especially those domains that are more 
ecological or that demonstrate the aesthetics and fallibility of mathematics. New domains, such as chaos theory, simulation and modeling, complexity theory, and fractal geometry offer a wide potential for mathematical understanding. Even where mathematical modeling and complexity analyses seem so suitable, nonetheless, there seems to be a need for an external ethical criterion to guide mathematical applications. For this reason, critical scholars including Bishop and Skovsmose emphasize that it is crucial for school mathematics as well as science curricula to cultivate strong human and societal values that, for long, lay outside these elitist disciplines.

At a time when former colonies are trying to design mathematics curricula that are appropriate and suitable for their needs, discourses in global competitiveness and cultural uniformity accelerate the internationalization of the Euro-American curricula (and I should add the Japanese mathematics curriculum). New campaigns for equal standards to maximize global mobility champion the need for an international mathematics curriculum. The World Bank and donor agencies encourage developing countries to adopt curricula that are similar to those in Western countries. In contrast to the position of the World Bank, Fasheh (1997) articulated the insensitivity and unresponsiveness of the current Palestine mathematics curriculum to the culture, experiences, and realities of the Palestinians. In Africa, Gerdes (1999) sought to uncover and assimilate, what he referred to as, "frozen" mathematical aspects of African society (such as geometrical ideas in ornamentation and in construction) into the Mozambican curriculum.

\section{School Mathematics as a Critical Filter for Status}

In the last two decades, mathematics educators such as Apple (1992) have examined how students' linguistic, ethnic, racial, gender, and socio- economic backgrounds influence learning. Historically marginalized students, especially in places of escalating cultural and economic diversity such as the United States and the United Kingdom, have had lower 
scores on standardized mathematics tests. Educators in these countries have advocated for educational reforms that aim at accelerating the achievement levels of marginalized students. First scholars campaigned for and studied the relationship between mathematics learning and gender. Gender research ushered in campaigns for and research on mathematics learning by other minority groups. By the 1990s studies reviewing national trends illustrated: the gap in achievement, especially on basic skills, between White students and Hispanic and Black students in the United States was narrowing. However, recent analyses of, for instance, the American National Assessment of Educational Progress (NAEP) data indicate that in the 1990s the achievement gaps in mathematics between racial and ethnic groups reversed their directions and began to widen again (Lee, 2002). Also, the data revealed further complexities (Tate, 1997); For instance, a trend analysis of the period from 1973 to 1992 indicated that in the United States: males still outperformed females on College Admission and Advanced Placement Calculus examinations; English language proficiency was positively correlated with mathematics performance for the Hispanic- and African-American students but not for the Asian- American students; Socio economic status appeared to affect the performance of Asian-American students more than their counterparts (Tate, 1997). These complexities imply that attempts to close the achievement gap by assimilating students of minority groups into the mainstream of White-male students, if achievable, might not be appropriate. It appears very little is known about constraints to mathematical achievement. There is, therefore, need for more investigations - asking broader questions - toward understanding the elusive relationships between social and cultural differences and learning mathematics. Walkerdine's (1990) study of how socioeconomic difference, such as being a first generation immigrant black girl from a working class family, is lived under various discursive practices appears to be of relevance. Walkerdine emphasized that mathematical thinking processes, such as abstraction, are discursive practices that have been made available to a select population on the basis of social 
and historical precedent.

With the current pace of change in technology, some scholars caution that by emphasizing facts and procedures at the expense of attitudes and ways of thinking the school system is mostly preparing students for jobs that may not exist by the time they graduate (Davis, P. \& Hersh, 1981; D’Ambrosio, 2001). The tacit education for work goal of mathematics education (or schooling in general) in times of rapid technological change seems irrelevant, they argue. As well in some countries, particularly in countries where the examination system is used to select students for further education or for job qualification, the basis for the requirement of formal mathematics is rarely demonstrated. Davis, P. and Hersh (1986) note that there is need for a re-examination of instances where mathematics courses such as pure mathematics (as opposed to applied mathematics) are unjustly used as gatekeepers to create new classes. In an education system that is designed mainly to serve economic development there must be a gatekeeper; indeed, mathematics had it been as culturally and socially free as had always been thought, would have been a more reasonable gatekeeper than gender, socio-economic status, race, or tribes. Nevertheless, this is unjust to the individuals who because of poor mathematics grades are denied access to further education. The use of mathematics as a gatekeeper to educational and job opportunities is also unjust to society because mathematics can no longer be considered culturally- and socially-neutral. Furthermore, an exclusive bias towards formal and abstract mathematics generates an illusion of certainty among the public that is especially unjust. Both the use of mathematics as a sieve and the illusions of validity generated by mathematics users serve to exclude the participation of majority of lay people in decision-making and in comprehension of decisions made. 


\section{School Mathematics and Educational Reform}

Reform of mathematics education has swung from a focus on content and psychological aspects, to, at present, a deeper consideration of societal factors. As Galbraith (1988) notes, the directives of education are never free of the social and political systems in which they operate at a given time and place. At the turn of the $20^{\text {th }}$ century, issues of content dominated school mathematics reform, replacing issues of individual psychology. In the last few decades, the talk has been "mathematics for all", "back to the basics" and "minimum competence." Towards the end of the $20^{\text {th }}$ century, the concern has been about how the individual student constructed his or her knowledge. Walkerdine (1990) notes that even the theories of child development that are regulating education are themselves "a product of a certain world-view produced out of the European models of mind at a moment in the development of European capitalism dependent on colonization and domination of the other, held to be different and inferior" (p. 52). To the extent that mathematics education research, as a medium for informing practice, rarely made reference to the economic, cultural, political, and social aspects, it may not be above the critique.

\section{Traditional Mathematics Teaching and Research}

School mathematics in its traditional setting has always tended to overlook the experiences the child comes with to the classroom. Instead, it has tended to seek to resolve misconceptions, to transform and intellectualize the child for the "child's own good." Implicit in the traditional mathematics instruction are particular, narrow perspectives of both learning and childhood. Individual-centered learning and most psychological approaches to learning themselves appear to be connected with societies for which absolute individual autonomy rather than social interaction and responsibility is preferred (Jardine, 1998). Current reform principles such as those advocated for by the National Council of Teachers of Mathematics promote the view of learning as a social activity. Nonetheless, teaching is still 
dominantly guided by the prevailing culture in which child growth and development toward adulthood (or completeness) is the most important value. Yet, the child- development view is coming under increasing critique, as evidenced in the following:

Once we have used these concepts and linked processes of physical and mental change to a valued state of being or becoming, we have already negatively estimated a child as an inferior version of the adult ... [one] that needs to be educated as a ward. (Nandy, 1987, p. 56)

If children (and Southern cultures) are to be meaningfully involved in what they learn and how they learn, educators and policy makers may want to approach them from a more dialogical framework.

The very teaching of traditional mathematics itself raises the issue of how access to mathematical knowledge is controlled. In a more traditional classroom, there is a rigid notion of truth that is reinforced as the teacher and/or textbooks are the sole source to evaluating the correctness of an answer. Usually problems presented to students are stripped of their social and practical contexts, while the language employed elevates agency from humans to mathematical processes. For example, in the clause, "A $180^{\circ}$ rotation gives you ..." the actor is rotation and not the person.

Denvir (1988) asserts that teaching problem-solving strategies may simply involve coaching and cramming, and rehearsed responses to evaluative assessment aimed at covering up weakness and encouraging students to adopt mechanistic behaviors. Scholars such as Denvir argue that even some of the most recent research based reforms such as teaching heuristics might not be solutions but rather symptoms of problems of modern schooling. Examination preparation wars and research solely aimed at improving performance have arisen to counteract competitive examination systems that determine the life chances of students (Spring, 1998). 


\section{Mathematics as an Instrument of Power}

As critical theorists observe, the project of school mathematics reinstates an ideology of certainty that pervades society. Borba and Skovsmose (1997) assert that the ideology of certainty transforms mathematics into a "language of power." Phrases such as "it is mathematically proven," "the simulated model assures that," and "the numbers speak for themselves" suffuse political, economic, and social discourse. This objectivist discourse appears to be occasioned by the traditional mathematical discourse coupled with the dominant ideology of scientific determinism.

Even more insidious the character of the traditional mathematics pedagogy enhances a search for mathematical truths and correctness external to "Man." In the absolutist view, mathematical truth is not only attainable but proofs of truthfulness are available. Such a philosophy of mathematics as a pure, perfect system and an infallible tool pervades society. In turn, ideas about mathematical truth are incorporated into truth about human subjects and about ecology in general. The fallibility of mathematical truth, of which the majority of mathematicians are fully cognizant, never seems to penetrate school mathematics and, consequently, many policy makers hold the absolutist view.

Trickett and Sulke (1988) observe that the view of mathematics held by most people is very narrow; that is, it is of a body of established knowledge and procedures - facts and rules. This literalist view leaves out the integral parts of mathematical activity that mathematicians engage in, for example, the role of mathematics in decision-making and communicating, the interplay of internal coherence with correspondence with physical reality in developing mathematical theories, and the awareness that most mathematical conclusions are value-laden. One is left to wonder about the potential harm that an authoritarian pedagogy and a literalist view of mathematics reinforce. To challenge the ideology of certainty, reform researchers have suggested the incorporation of, among others, investigations, project work, 
and dialogue in mathematics classrooms; however, these alternatives have not been received without resistance themselves. Politicians, voters, parents, teachers and, even, students themselves have, with nostalgia, voiced their preference for a more familiar form of mathematics that is factual, procedural, and technical. To them, it is abominable for a mathematics classroom to engage in collaborative and socially proactive learning. For example, Margaret Thatcher voiced her resistance to the inclusion of social issues in the mathematics curriculum, claiming, "Children who need to be able to count and multiply are learning anti-racist mathematics - whatever that may be" (cited in Pimm, 1988, p. 69).

Is academic mathematics really free of human influences and above humanity, in the intentional ambiguity of the term humanity? Chassapis' (1997), for instance, analyzes real world situations utilized in the current Greek curriculum and illustrates the prevalence of financial especially commercial situations devoid of any pertinent social relationships. For example, for the fifth and sixth grade textbooks he analyzed, $70 \%$ of the real life situations were commercial situations introduced by statements such as “A store sells ...”, "a manufacture produces ...” (p. 26). He claims that such applications indoctrinate children into the ideology of middle-class mercantile. Recently, curriculum developers and textbook publishers have responded to such criticisms by embedding mathematical problems in social and cultural situations. Nonetheless, some efforts towards a more responsive mathematics curricula are still largely cosmetic (i.e., by additions of colorful pictures and surreal stories in textbooks). 


\section{Concluding Remarks}

The utilitarian view of school mathematics, in which mathematics is sanctioned to provide expertise while students are compelled to take mathematics "for their future," has resulted in what Abraham and Bibby (1988) refer to as the industrially oriented mathematics curriculum. This view is summed up by Apple's (1992) assertion:

One of the primary reasons mathematical knowledge is given high status in current reform efforts is not because of its beauty, internal characteristics, or status as a constitutive form of human knowing, but because of the socio-economic utility for those who already possess economic capital. (p. 423) Reconceptionalist scholars are concerned that an industrially oriented curriculum reduces the environment to material resources and human beings to human resources. Such a curriculum also reduces knowledge to a commodity to be sorted by the labor market using examinations as filters. Students become consumers of mathematics whose democratic and humane participation in learning is extraneous to their aspiration for socio-economic advantage. It ought to be widely acknowledged that mathematics (like other academic disciplines) still has a variety of values including aesthetic, philosophical, historical, psychological, and pedagogical. As mathematics educators, it appears crucial that we address a number of issues. What are the costs of a socio-economic utilitarian view to mathematics education, or to education in general? What about the aesthetic, religious, and recreational purposes of mathematics that are foundational to the historical development of mathematical knowledge?

Historically, the value of numbers, for instance, ranges from more than a tool of commerce to a tool of wonder and lore (such as the value of numbers in beliefs, mores, superstition, symbolism, and occult). This is true for both the Greek and the peripheral cultures. The Pythagoreans of Greece and the ancient Hebrews nearly made an occult of numbers such as one, three, and four. For example, the unmentionable name of God had four letters - IHVH, there were four ages, four seasons, four winds, four senses, and so on. Likewise, for the Indic cultures, four was the most popular sacred number (Julian, 1994). In 
so far as we teach mathematical capabilities as ideal (almost divine) knowledge severed from human activity, and in so far as we tend to unreflectively privilege pure mathematics over applied mathematics, our students are likely to be experiencing mathematics as an alien religious intuition or ritual.

In a way, the increased application of mathematical technologies and inventions has meant an increased status for mathematics. More aspects of the human and physical world are being mathematized and people are increasingly conceptualizing the world in mathematical terms. Yet, in most cases this has meant that more and more parts of the world that are not or cannot be mathematized are unconsciously adjusted to fit abstract models, thrown away, or eventually cease to exist (Davis, P. \& Hersh, 1986).

We should never forget that a stroll in the woods or a deep conversation with new or old friends are beyond mathematics, and then, when we go back to our jobs as administrators, teachers, [researchers] or whatever, let us still remember that numbers are only the shadow, that life is the reality. (p. 98)

Since mathematical thinking has been made central to almost all school curricula, the school mathematics project is central to and responsible for fostering the conscientization of students. The synthesis of the critical discourses offered in this essay has practical implications for the education systems with which I am familiar, both in the North and South. The implications include:

- Teaching mathematics as a human activity (rather than non- corporeal knowledge) as is promoted by situated and ecological cognition scholars.

- Re-examining the place of history in modern mathematics.

- Having teachers together with researchers, with the help of ethnomathematicians, explore culturally different mathematical paradigms that are relevant to their respective students.

- Encouraging educators, researchers, and policy makers to open up critical debate on the role of Western mathematics in controlling the grounds for scientific knowledge. 
- Challenging researchers to adopt postmodern conceptual frameworks that pay attention to broader social, political, and ecological aspects in addition to psychological and classroom aspects of learning.

- Encouraging educators and curriculum developers to explore mathematical inventions that demonstrate both the power and fallibility of mathematics.

- Also, in light of the heightened tendency toward universalized curriculum there is a need to explore ways in which classrooms, schools, regions, and nations could benefit from locally relevant curricula.

\section{NOTES}

1. Conscientization - the cultivation of the critical and mindful conscious of the individual and society at large.

2. D'Ambrosio later revised this definition to the "art or technique of explaining, understanding, coping with (mathema) the social cultural and natural (ethno) environment" (D’Ambrosio, 1990, p.1184).

I take full responsibility of the ideas developed in this paper. I am grateful, however, to my advisors Dr. D.G. Smith and Dr. B. Davis for reading, editing, and critiquing this manuscript, right from its early conception. Thanks to Dr. E. Simmt, my advisor and supervisor for nurturing my work and thoughts from which this essay is one of the artefacts.

\section{Author's Address:}

Secondary Education Faculty of Education 341 Education South University of Alberta Edmonton, Alberta CANADA T5G 2E2

EMAIL: namukasa@ualberta.ca 


\section{REFERENCES}

Abraham, J. \& Bibby, N. (1988). Mathematics and society: Ethnomathematics and a public educator curriculum. For the Learning of Mathematics, 8(2), 2-11.

Apple, M.W. (1992). Do the standards go far enough? Power, policy and practice in mathematics education. Journal of Research in Mathematics Education, 23, 412-431.

Bishop, A.J. (1997). Western mathematics: The secret weapon of cultural imperialism. In B. Ashcroft (Eds.), Post colonial studies reader (pp. 71- 76). London: Routledge.

Borba, M.C., \& Skovsmose, O. (1997). The ideology of certainty in mathematics education. For the Learning of Mathematics, 17(3), 17- 23.

Chassapis, D. (1997). The social ideologies of school mathematics applications: A case study of elementary school textbooks. For the Learning of Mathematics, 17(3), 24-26.

Confrey, J. (1995). The theory of intellectual development. For the Learning of Mathematics, 15(2), 36-45.

Confrey, J. (1999). Voice, perspective, bias and stance: Applying and modifying Piagetan theory in mathematics education. In L. Burton (Ed.), Learning mathematics, fromhierarchies tonetworks (pp.3-20). London: Falmer Press

Davis, B. (2001). Why teach mathematics to all students? For the Learning of Mathematics, 21(1), 17-24.

Davis, P.J. \& Hersh, R. (1981). The mathematical experience. Boston: Birkhäuser.

Davis, P.J. \& Hersh, R. (1986). Descartes' dream: The world according to mathematics $\left(1^{\text {st }}\right.$ ed.). San Diego: Harcourt Brace Jovanovich.

D’Ambrosio, U. (1985). Ethnomathematics and its place in the history and pedagogy of mathematics. For the Learning of Mathematics, 5(1), 44-48.

D’Ambrosio, U. (1990). The role of mathematics education in building democratic and just society. For the Learning of Mathematics, 10(3), 20-23.

D'Ambrosio, U. (2001). What is ethnomathematics, and can it help children in schools? 
Teaching Children Mathematics, 7(6), 308-310.

Denvir, B. (1988). What are we assessing in mathematics and what are we assessing for? In D. Pimm (Ed.), Mathematics and teacher education (pp. 128-140). London: Hodder \& Stoughton.

Fasheh, M. (1997). Is math in the classroom neutral - or dead? Aview from Palestine. For the Learning of Mathematics, 17(2),24-27.

Galbraith,P.(1988). Mathematics education and the future: Along wave of change. For the Learning of Mathematics, 8(3), 27-33.

Ghever Ghese Joseph, G. (1991). The crest of the Peacock: Non-European roots of mathematics. London: Penguin Books

Gerdes, P. (1999). Geometry from Africa: Mathematical and educational explorations.

Washington, DC: The Mathematical Association of America.

Julian, B. (1994). The lore of numbers. In F. Swertz (Ed.), From five fingers to infinity: A journey through the history of mathematics (pp. 97-101). Chicago: Open court.

Jardine, D.W. (1998). To dwell with a boundless heart: Essays in curriculum theory, hermeneutics, and the ecological imagination. New York: Peter Lang.

Kachur, J. \& Harrison, T. (1999). Public education, globalization, and democracy: Whither Alberta? In T. Harrison \& J. Kachur (Eds.), Contested classrooms (pp. xiii-xxxiv). Edmonton, AB: University of Alberta.

Lakoff, G. \& Núñez, R.E. (2001). Where mathematics comes from: How the embodied mind brings mathematics into being. New York: Basic Books.

Lee, J. (2002). Racial and ethnic achievement gap trends: Reversing the progress toward equity. Educational Researcher, 31(1), 3-12.

Moore, C.G. (1994). Research in Native American mathematics education. For the Learning of Mathematics, 14(2), 9-14.

Nandy, A. (1987). Reconstructing childhood. Traditions, tryranny, and utopias: Essay in the 
politics of awareness. Delhi: Oxford.

Pimm, D. (1988). Mathematics and teacher education. London: Hodder \& Stoughton.

Pinxten, R. (1994a). Anthropology in the mathematics classroom? In S. Lerman (Ed.), Cultural perspectives on the mathematics classroom (pp. 85-114). Dordrecht, NL: Kluwer Academic Publishers.

Pinxten, R. (1994b). Ethnomathematics and its practice. For the Learning of Mathematics, 14(2), 23-25.

Polya, G. (1957/1973). How to solve it: A new aspect of mathematics $\left(2^{\text {nd }}\right.$ ed.). Princeton, NJ: Princeton University Press.

Saxe, G.B., \& Posner, J. (1983). The development of numerical cognition. In H.B. Ginsburg (Ed.), The development of mathematical thinking (pp. 292-318). New York: Academic Press.

Skovsmose, O. (1990). Mathematical education and democracy. Educational Studies in Mathematics, 21, 109-128.

Sleeter, C.E. (1997). Mathematics, multicultural education, and professional development. Journal of Research in Mathematics Education, 28, 680-696.

Smith, D.G. (2000). The specific challenges of globalization for teaching and vice versa. The Alberta Journal of Educational Research, 46 (1), 7-26.

Spring, J. (1998). Education and the rise of the global economy. Mahwah, NJ: Lawrence Erlbaum.

Tate, F.T.(1997). Race-ethnicity, SES, gender, and language proficiency in mathematics achievement: An update. Journal of Research in Mathematics Education, 28, 652-679.

Trickett, L. \& Sulke, F. (1988). In D. Pimm (Ed.), Mathematics and teacher education (pp. 109-117). London: Hodder \& Stoughton. 
Vithal, R. \& Skovsmose, O (1997). The end of innocence: A critique of 'Ethnomathematics.' Educational Studies in Mathematics, 34, 131- 157

Walkerdine, V. (1990). Difference, cognition, and mathematics education. For the Learning of Mathematics, 10(3), 51-55.

Wright, P. (1998). Maths and human rights education. Mathematics Teaching, 163, 58-59.

Zaslavsky, C. (1994). “Africa counts” and ethnomathematics. For the Learning of Mathematics, 14(2), 2-6. 